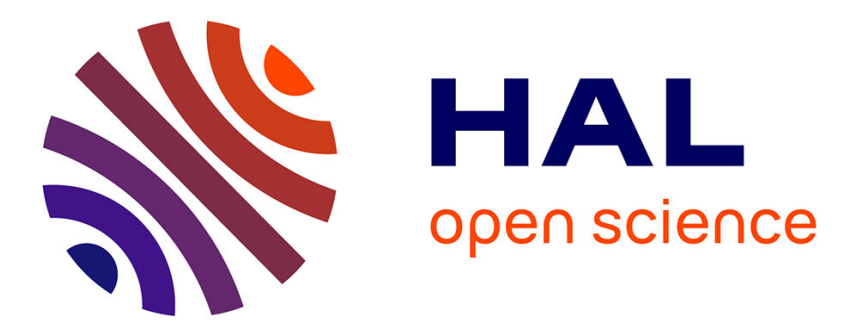

\title{
A modified Beremin model to simulate the warm pre-stress effect
}

\author{
W. Lefevre, G. Barbier, Renaud Masson, G. Rousselier
}

\section{To cite this version:}

W. Lefevre, G. Barbier, Renaud Masson, G. Rousselier. A modified Beremin model to simulate the warm pre-stress effect. Nuclear Engineering and Design, 2002, 216 (1-3), pp.27-42. 10.1016/S00295493(02)00067-5 . hal-03427479

\section{HAL Id: hal-03427479 \\ https://hal.science/hal-03427479}

Submitted on 13 Dec 2021

HAL is a multi-disciplinary open access archive for the deposit and dissemination of scientific research documents, whether they are published or not. The documents may come from teaching and research institutions in France or abroad, or from public or private research centers.
L'archive ouverte pluridisciplinaire HAL, est destinée au dépôt et à la diffusion de documents scientifiques de niveau recherche, publiés ou non, émanant des établissements d'enseignement et de recherche français ou étrangers, des laboratoires publics ou privés. 


\title{
Article publié dans \\ Nuclear Engineering and design, 2002, \\ vol. 216, no 1-3, p. 27-42.
}

\section{A modified Beremin model to simulate the warm pre-stress effect}

\author{
W. Lefevre ${ }^{\mathrm{a}, \mathrm{b}}$, G. Barbier ${ }^{\mathrm{a}}$, R. Masson ${ }^{\mathrm{a}, *}$, G. Rousselier ${ }^{\mathrm{a}}$ \\ a Electricité de France, Division Recherche et Développement, Les Renardières, F-77818 Moret-sur-Loing, France \\ ${ }^{\mathrm{b}}$ Materialprüfungsanstalt (MPA), Universität Stuttgart, Pfaffenwaldring 32, D-7000 Stuttgart 80, Germany
}

Received 14 June 2001; received in revised form 15 February 2002; accepted 15 February 2002

\begin{abstract}
Starting from the pioneering work of Beremin (Met. Trans. A 14A (1983) 2277), a modified Beremin model is proposed. As a result of temperature effect on mechanical fields heterogeneity at the micromechanical scale, an apparent temperature dependence of the macroscopic cleavage stress is first introduced to fit correctly the brittle to ductile transition. Then, the classical Beremin-Weibull fracture probability expression is extended to take account of non monotonic thermomechanical loadings. The modified Beremin model is applied to warm pre-stress (WPS) tests performed on low alloy ferritic steel compact tension specimens (see IAEA Specialists' meeting, Rockville (2000)). Apart from 'load-unload-cool-fracture' (LUCF) cycles, for which additional investigations are needed, these simulations are in good agreement with experiments provided that an additional microcrack propagation condition is introduced, namely, necessary slip activity. This additional condition is consistent with the classical Beremin model restricted to monotonic loading paths.
\end{abstract}

\section{Introduction}

Experimental evidences of the so-called 'warm pre-stress (WPS) effect' were first reported nearly 40 years ago (Brothers and Yukawa, 1963). Since then, it has been experienced in several works concerning ferritic steels (see for example Lidbury and Birkett, 1990). Basically, this effect is associated with the following experimental result: a cleavage fracture toughness enhancement at low temperature is obtained after a pre-loading at a higher temperature. Further experimental investi-

* Corresponding author.

E-mail address: renaud.masson@edf.fr (R. Masson). gations assessed the so-called 'conservative principle': there is no fracture if the stress intensity factor decreases (or is held constant) while the crack-tip temperature decreases, even if the virgin material toughness is reached.

Considering assessment of nuclear pressure vessel integrity during a pressurized thermal shock (PTS; for example, a loss of coolant accident (LOCA)) this conservative principle is of the greatest importance. However, to assess the margin corresponding to this effect for a given thermal shock, a quantitative analysis is required. Beremin model has been used in the past to simulate the WPS effect in the frame of local approach to fracture (see for example Mudry, 
1985). Unlike the 'global' modeling of fracture, the 'local' approach is based on a local fracture criteria which should be consistent with simulations of non monotonic loading paths such as WPS ones. Simulating the whole WPS loading path requires first to fit correctly the brittle to ductile transition curve. That is the reason why recent works (Kordisch et al., 2000) proposed to modify this model introducing a temperature dependence of the Beremin cleavage stress parameter. Preliminary results obtained with this approach are encouraging.

In this paper, we aim at developing this approach in a more complete way. Starting from the original Beremin model, the fracture probability expression for a structural component is derived considering both temperature dependence of the cleavage stress as well as unloading effects. Then, this modified Beremin model is applied to a WPS recent experimental program (Lefevre et al., 2000) concerning 18MND5 (A533B) ferritic steel. Numerical finite element simulations of the whole loading path are compared with experimental results.

\section{Modified Beremin model}

In the following, we consider a structural component (volume $\Omega$ ) submitted to a thermomechanical loading. Assuming this prescribed loading to be zero for times $t \leq 0$, we are search-

Table 1

Chemical composition of 18MND5 (A533B) steel (wt.\%)

\begin{tabular}{lllllllllllll}
\hline $\mathrm{C}$ & $\mathrm{Mn}$ & $\mathrm{Si}$ & $\mathrm{Ni}$ & $\mathrm{Cr}$ & $\mathrm{Mo}$ & $\mathrm{Cu}$ & $\mathrm{S}$ & $\mathrm{P}$ & $\mathrm{Al}$ & $\mathrm{V}$ \\
\hline 0.19 & 1.5 & 0.23 & 0.66 & 0.17 & 0.485 & 0.084 & $<0.001$ & 0.004 & 0.011 & 0.004 \\
\hline
\end{tabular}

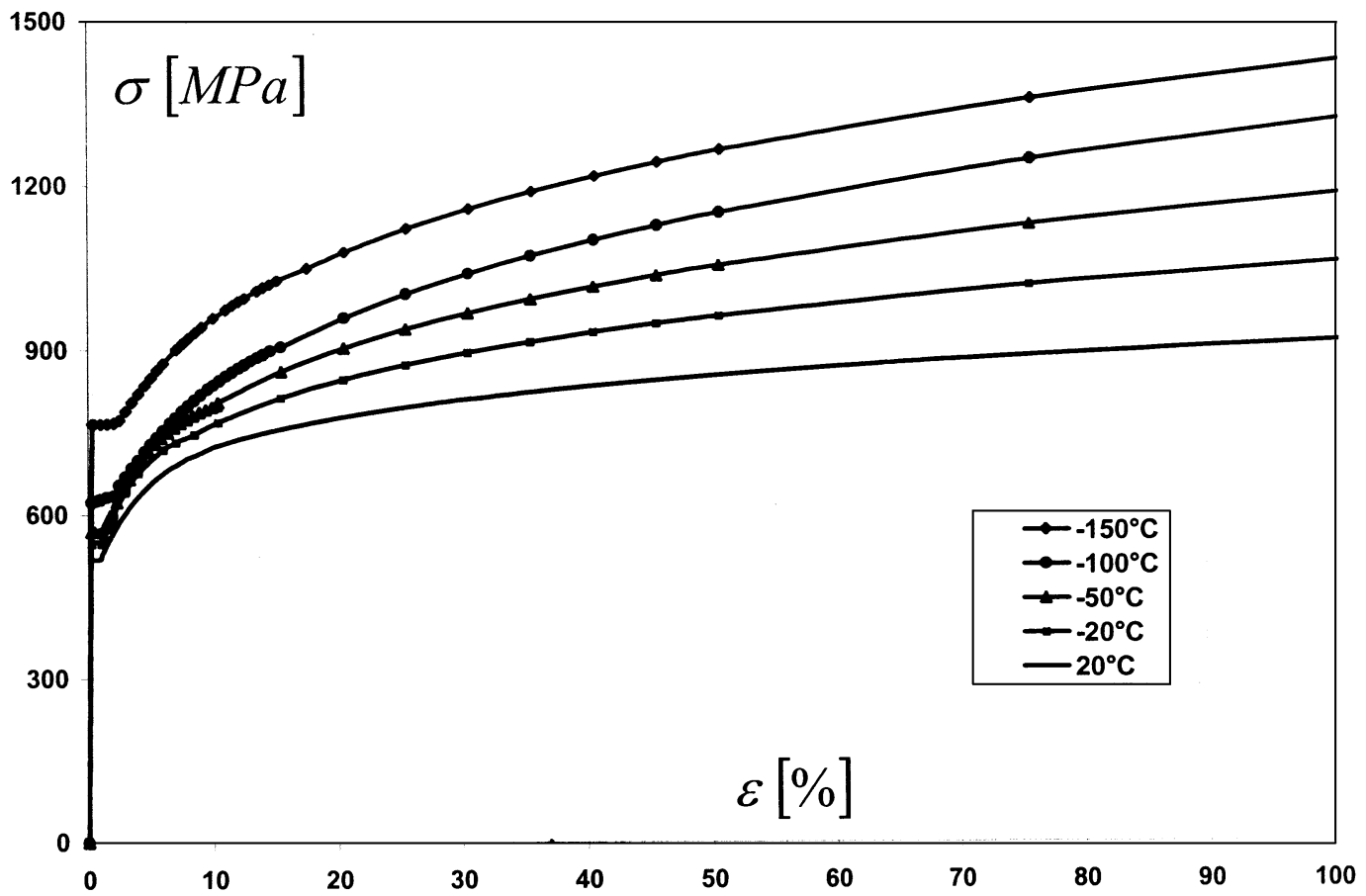

Fig. 1. Tensile stress-strain curves of 18MND5 (A533B) ferritic steel at five different temperatures. 


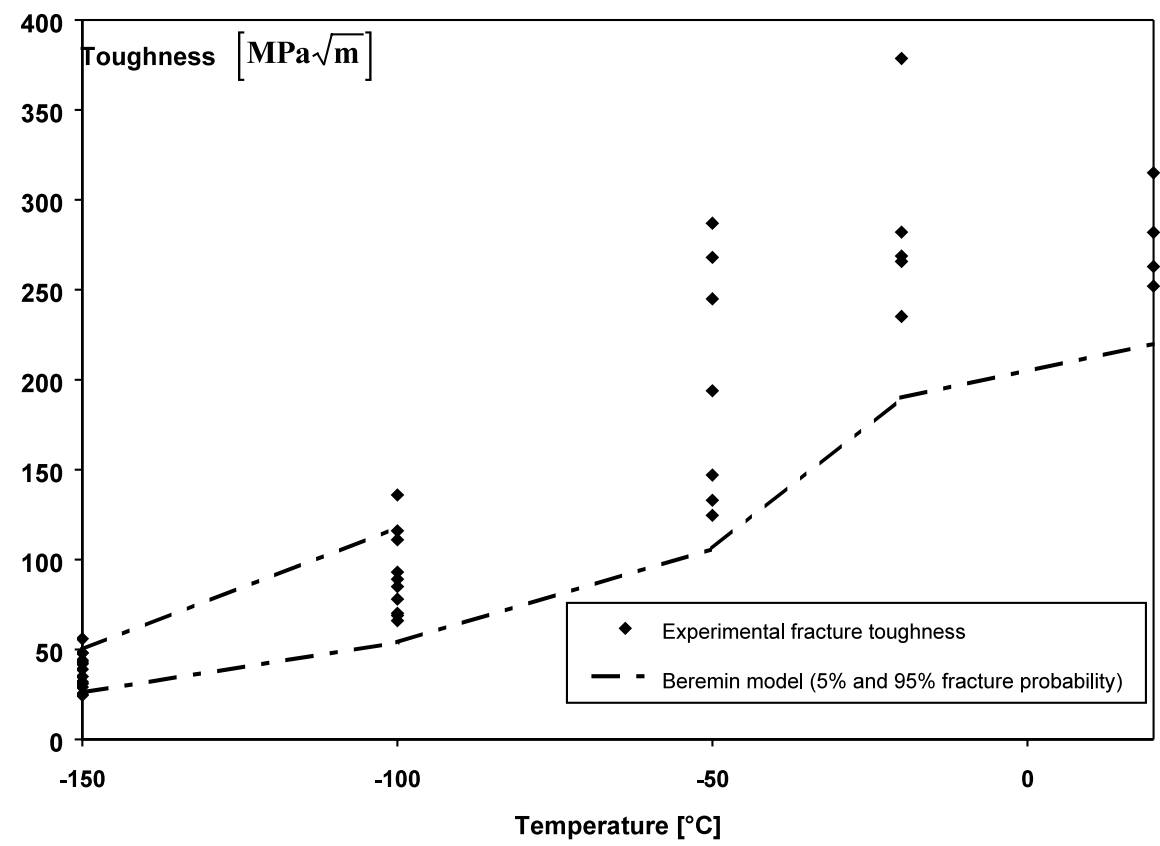

Fig. 2. Evolution of the fracture toughness in the brittle to ductile transition as predicted by the Beremin model (parameters given in Table 2) compared with experimental results between -150 and $20{ }^{\circ} \mathrm{C}$. The lower and upper curves correspond to a fracture probability of 5 and $95 \%$, respectively.

Table 2

Cleavage stress as a function of temperature (the Weibull modulus $m$ equals to 20.6)

\begin{tabular}{lrrrr}
\hline Temperature $\left({ }^{\circ} \mathrm{C}\right)$ & -150 & -100 & -50 & -20 \\
$\sigma_{\mathrm{u}}(\mathrm{MPa})$ & 2920 & 3140 & 3370 & 3820 \\
\hline
\end{tabular}

ing for the cumulative fracture probability of this component at a given positive time $t$, i.e. $P_{\mathrm{r}}(t)$.

\subsection{Original Beremin model}

Starting from experimental evidences of cleavage fracture, the Beremin (1983) model stands on a simplified description of nucleation and propagation of microcracks throughout the highly stressed part of structural components. According to previous works (Stroh, 1954; Cottrell, 1958), plastic deformation originates microcracks. Then, the propagation criterion of these microcracks leading to the brittle fracture of the whole component relies on a Griffith (1920) analysis: a given microcrak of length $a$ propagates if the normal stress exceeds the critical stress $\sigma_{\mathrm{c}}$ given by, $\sigma_{\mathrm{c}}=\sqrt{\frac{2 E \gamma}{\pi\left(1-v^{2}\right) a}}$,

where $E$ is Young modulus, $v$ Poisson ratio and $\gamma$ is the surface energy.

Considering a stressed volume element $\mathrm{d} V$, the material heterogeneity leads to an heterogeneous spatial distribution of potential cleavage sites associated to independent microcracks of different lengths. Equivalently, due to the disordered microstructure of the material, the critical stress of each site is a random spatial variable. Denoting by $g$ its density distribution function, the probability that the critical stress of a site is smaller than a given value of the applied stress $\sigma$ is:

$$
\int_{0}^{\sigma} g(u) \mathrm{d} u
$$




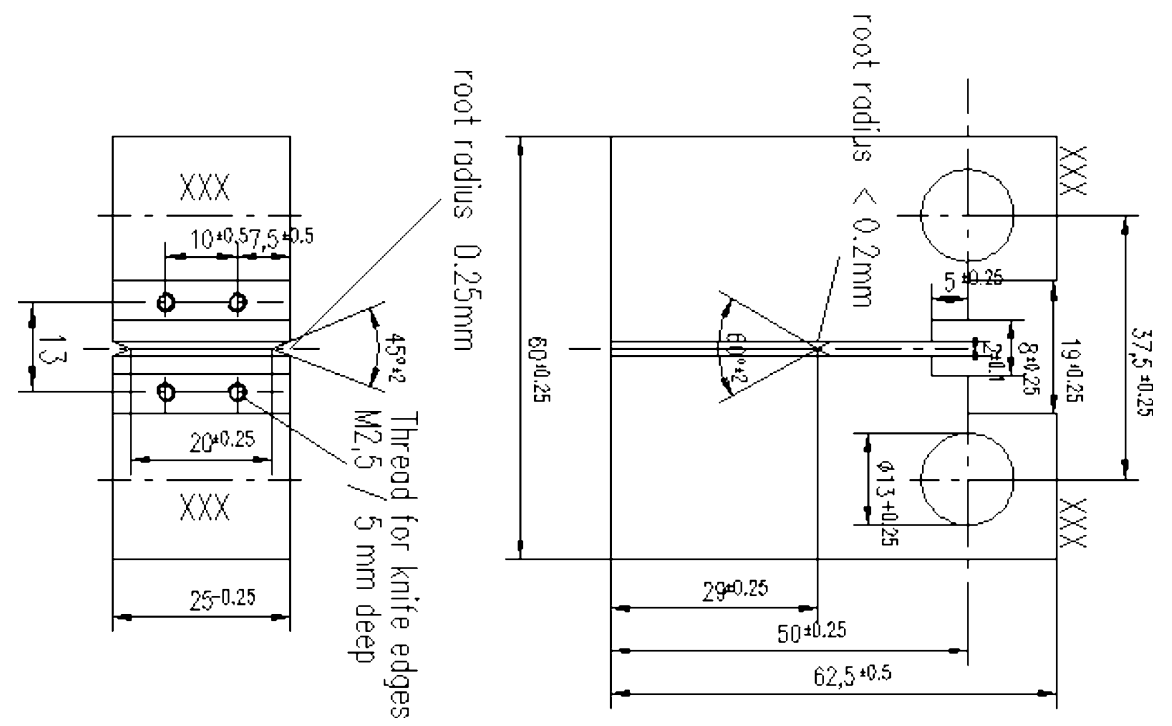

Fig. 3. CT-25 (1T-CT) specimen geometry.

In the following, $p_{\mathrm{r}}(t)$ denotes the cumulative fracture probability of a site at a given time $t$. As the strain and stress are assumed to be constant throughout $\mathrm{d} V$, this probability is uniform in $\mathrm{d} V$. Denoting by $V_{0}$ the volume associated to each site, the cumulative fracture probability of $\mathrm{d} V$ at a given time $t$ is (weakest link theory):

$p_{\mathrm{r}}(\mathrm{d} V, t)=1-\left(1-p_{\mathrm{r}}(t)\right)^{\mathrm{d} V / V_{0}}$

$\left(V_{0}\right.$ is about $50 \times 50 \times 50 \mu^{3}$ ).

We now consider the whole component. Assuming $p_{\mathrm{r}}(t)$ to be small, the cumulative fracture probability is approximately (weakest link theory):

$P_{\mathrm{r}}(t) \approx 1-\exp \left(-\int_{\Omega} p_{\mathrm{r}}(\mathrm{t}) \frac{\mathrm{d} V}{V_{0}}\right)$

At this stage, it is necessary to give the expression of the cumulative fracture probability of a site. Classically, this probability is zero if the nucleation condition at $t$ (i.e. cumulated plastic deformation $p(t)$ strictly positive in $V_{0}$ ) is not satisfied. Conversely, $p(t)>0$ yields:

$p_{\mathrm{r}}(t)=\int_{0}^{\sigma_{1}(t)} g(\sigma) \mathrm{d} \sigma$

where $\sigma_{1}(t)$ is the maximum principle stress in $V_{0}$ (and $\mathrm{d} V$ ). Assuming an asymptotic power law relation for the distribution of microcracks lengths, this expression is integrated, namely:

$p_{\mathrm{r}}(t)=\left(\frac{\sigma_{1}}{\sigma_{\mathrm{u}}}\right)^{m}$

( $m$ and $\sigma_{\mathrm{u}}$ are classical parameters of Beremin model). Introducing the Weibull stress $\sigma_{\mathrm{w}}$ as,

$\sigma_{\mathrm{W}}=\left[\int_{\Omega} \tilde{\sigma}_{1}^{m} \frac{\mathrm{d} V}{V_{0}}\right]^{1 / m}$ with

$\tilde{\sigma}_{1}=\left\{\begin{array}{c}\sigma_{1} \text { if } \mathrm{d} V \text { is plastically deformed } \\ 0 \text { otherwise }\end{array}\right.$

the cumulative fracture probability of the component is:

Table 3

Stress intensity factor at fracture $\left(K_{\text {frac }}\right)$ corresponding to LUCF, LCF and LOCF warm prestressing cycles

\begin{tabular}{llc}
\hline Cycle & $K_{\mathrm{WPS}}\left(\mathrm{Mpa} m^{1 / 2}\right)$ & $K_{\text {FRAC }}\left(\mathrm{Mpa} m^{1 / 2}\right)$ \\
\hline LCF & 98 & 110.4 \\
LCF & 98.6 & 108.5 \\
LCF & 98.7 & 113.5 \\
LUCF & 97.7 & 96 \\
LUCF & 98.7 & 104.3 \\
LUCF & 98.8 & 108.9 \\
LOCF & 60.0 & 70.8 \\
LOCF & 60.1 & 78.9 \\
\hline
\end{tabular}



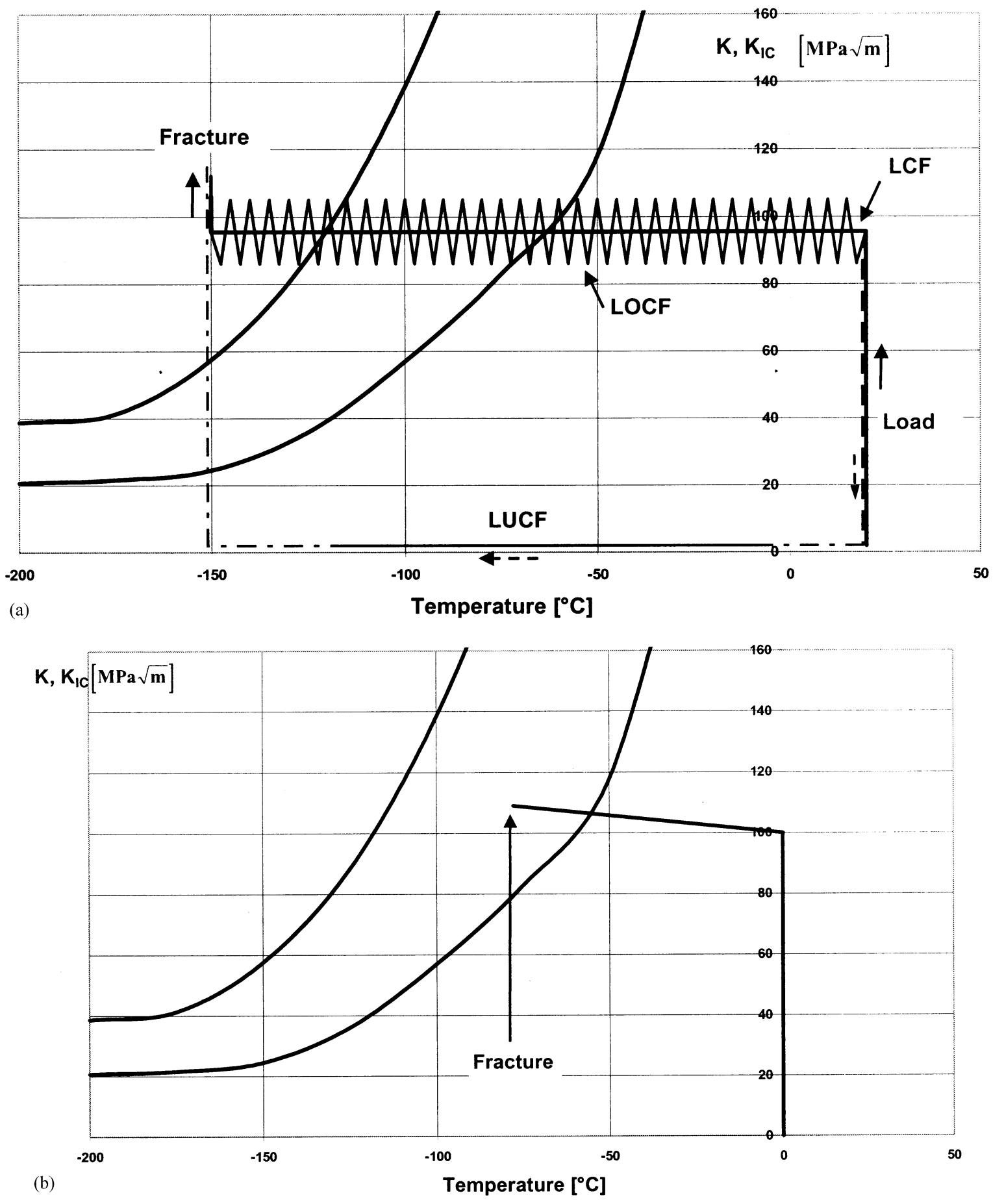

Fig. 4. (a) Thermomechanical paths experienced during LUCF, LCF and LOCF cycles. (b) Thermomechanical path experienced during the LM2CF cycle. The two curves represent the fracture toughness scatter band. 


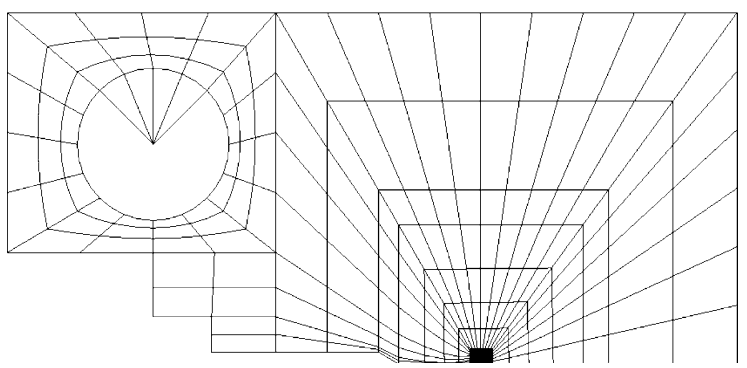

Fig. 5. Two dimensional mesh of the CT-25 specimen.
$P_{\mathrm{r}}=1-\exp \left(-\left(\frac{\sigma_{\mathrm{W}}}{\sigma_{\mathrm{u}}}\right)^{m}\right)$

Implicitly, expression (Eq. (5)) of $p_{\mathrm{r}}(t)$ implies that $\mathrm{d} V$ is submitted to a monotonically increasing mechanical loading. Therefore, a site of critical stress $\sigma_{\mathrm{c}}$ is not broken at a given time $t$ if:

$\sigma_{\mathrm{c}} \geq \sigma_{1}(u), \forall u \leq t$, such as $p(u)>0$,

condition which leads to relation (Eq. (5)) provided that the mechanical loading increases monotonically.

Table 4

Evolutions of the material parameters (kinematic hardening law (18)) with temperature

\begin{tabular}{|c|c|c|c|c|c|}
\hline Temperature $\left({ }^{\circ} \mathrm{C}\right)$ & -150 & -100 & -50 & -20 & 20 \\
\hline$\sigma_{0}(\mathrm{MPa})$ & 765.0 & 623.0 & 570.0 & 547.0 & 517.0 \\
\hline$C(\mathrm{MPa})$ & 2430.0 & 2710.0 & 3470.0 & 3360.0 & 3640.0 \\
\hline$\gamma$ & 4.4 & 4.9 & 7.7 & 8.7 & 12.0 \\
\hline
\end{tabular}

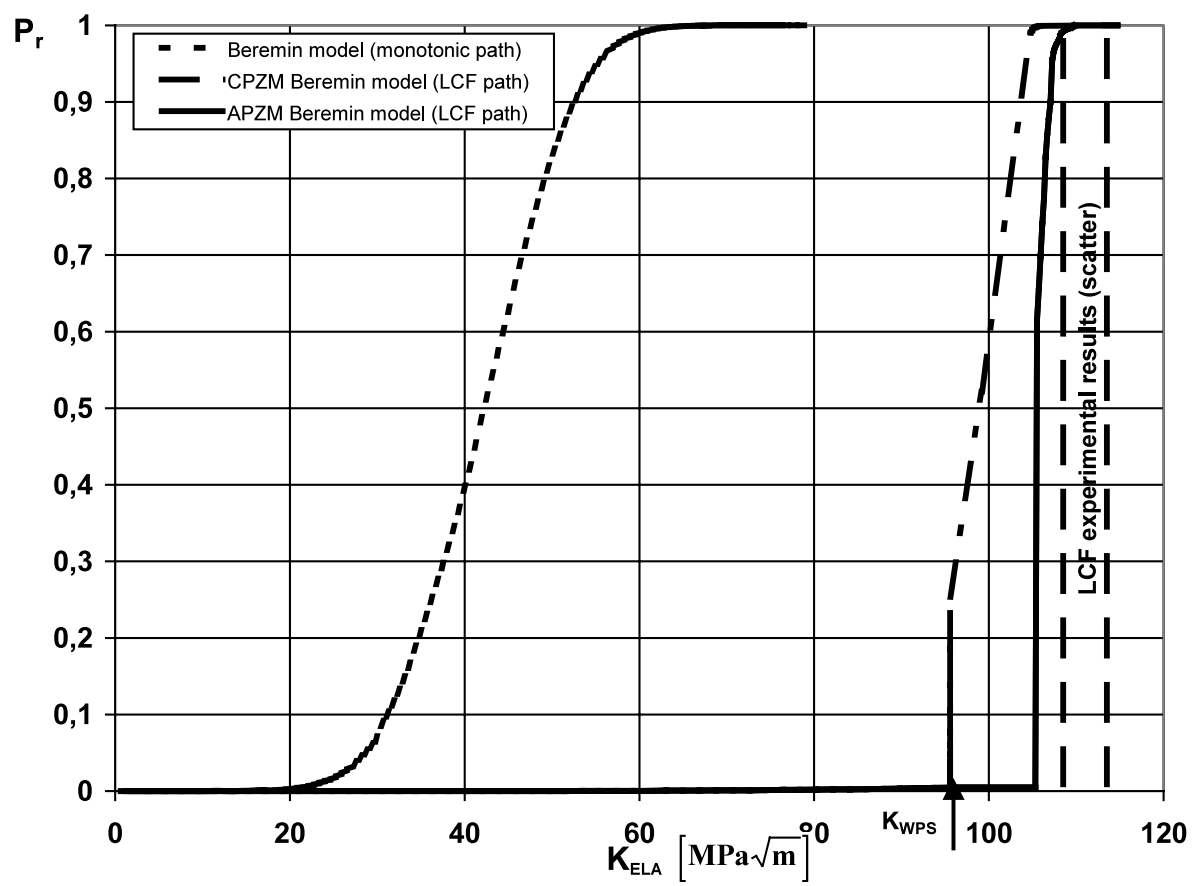

Fig. 6. Evolution of the cumulative fracture probability as a function of the elastic stress intensity factor during the LCF cycle as predicted by CPZM and APZM Beremin models (dotted-dashed and continuous lines, respectively). Evolution corresponding to the monotonic mechanical loading at $-150{ }^{\circ} \mathrm{C}$ is also reported (dotted line). These results are compared with experiments (the level of warm prestressing is indicated by a black arrow). 


\subsection{Extension to non monotonic mechanical loading}

We now consider a non monotonic mechanical loading. In this general case, the previous expression of the cumulative fracture probability is slightly modified. Denoting by $\sigma_{1}(u)$ the maximum principal stress in $\mathrm{d} V$ at any given time $u \leq t$, condition (Eq. (9)) now reads:

$\sigma_{\mathrm{c}} \geq \max _{\{u \leq t, p(u)>0\}} \sigma_{1}(u)$,

so that the cumulative fracture probability is:

$$
\begin{aligned}
p_{\mathrm{r}}(t) & =\int_{0}^{\max _{\{u \leq t, p(u)>0\}} \sigma^{\sigma_{1}(u)}} g(\sigma) \mathrm{d} \sigma \\
& =\left(\frac{\max _{\{u \leq t, p(u)>0\}} \sigma_{1}(u)}{\sigma_{\mathrm{u}}}\right)^{m} .
\end{aligned}
$$

\subsection{Apparent temperature dependence of the cleavage stress parameter}

In fact, mechanical fields are non uniform in the volume element $\mathrm{d} V$. The 'actual' normal stress to a given microcrack depends on the overall stress applied to this element in a non trivial way.

However, deriving a localization equation would need a specific model taking into account morphological and physical information about the material microstructure. Here, we simply assume that an approximate but pertinent relation is:

$\sigma_{1 \text { (micro) }}(t)=f \sigma_{1}(t)$,

where $\sigma_{1 \text { (micro) }}(t)$ denotes the effective microcrack stress at time $t$ and $f$ is a given localization parameter depending on the overall temperature $\theta$

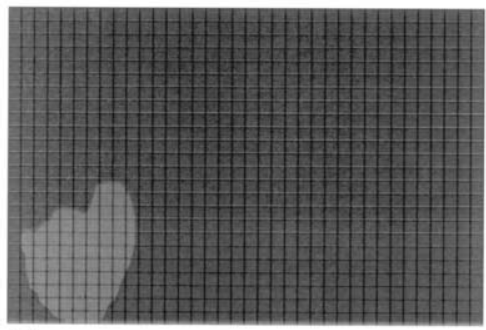

(1)

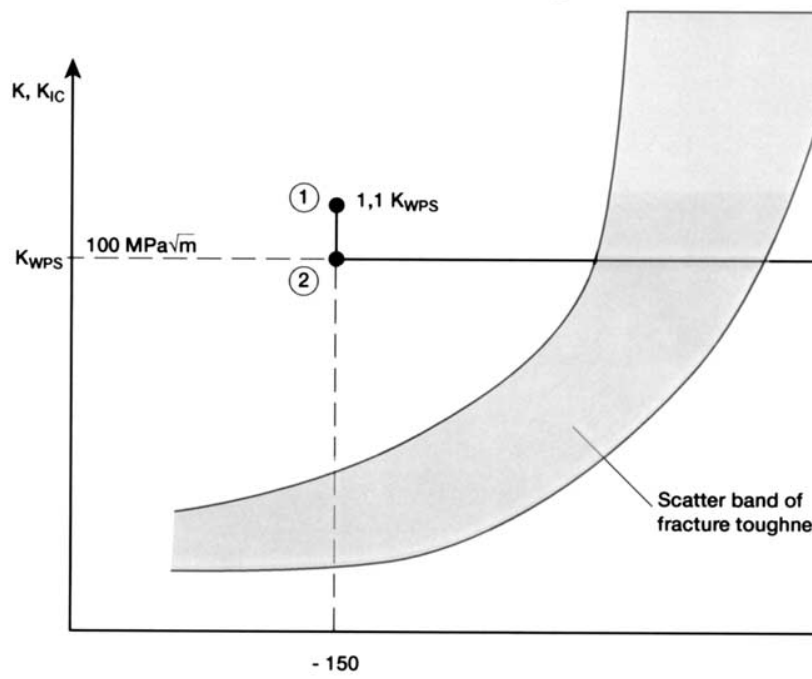

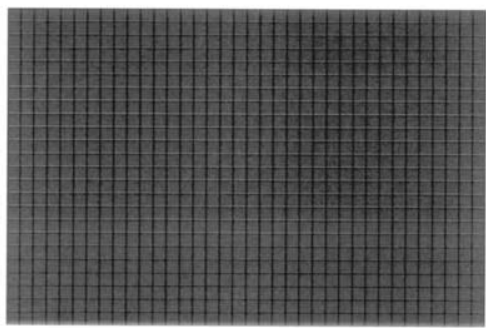

(2)

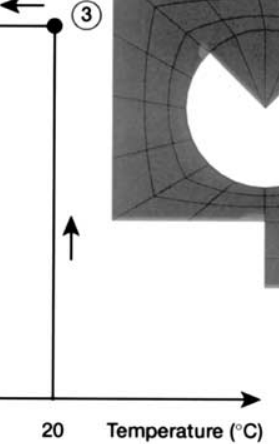

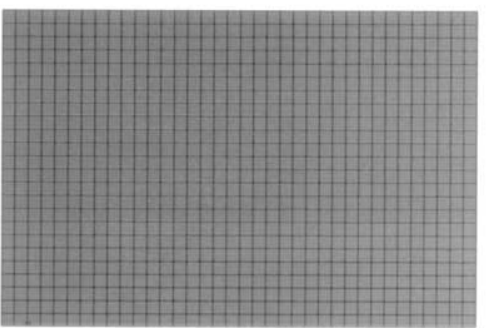

(3)

Fig. 7. Evolutions of active plastic zone (pale grey) at the crack tip at three different stages of LCF cycle: at the beginning (7-3) and the end (7-2) of cooling, at a cumulative fracture probability equal to 1 (7-1). 


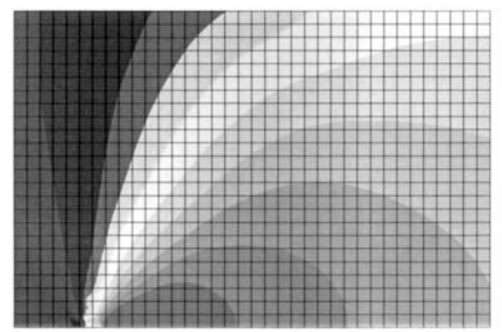

(1)

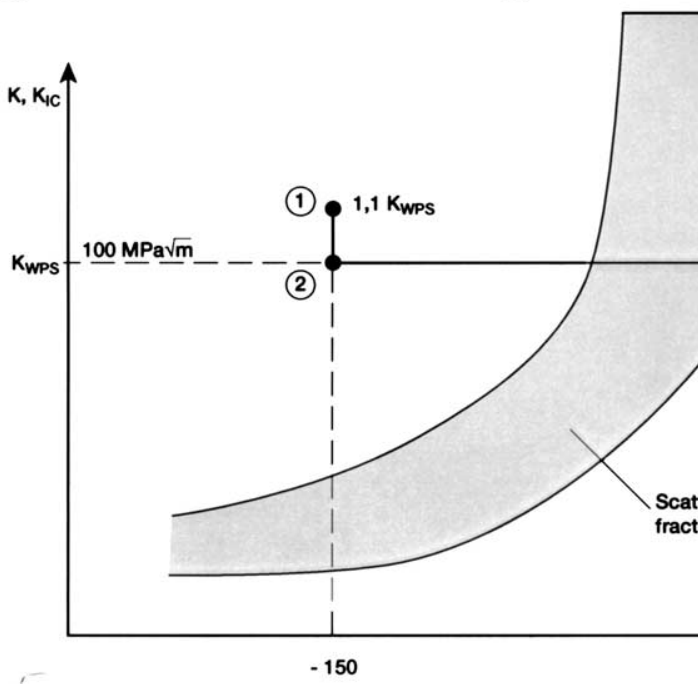

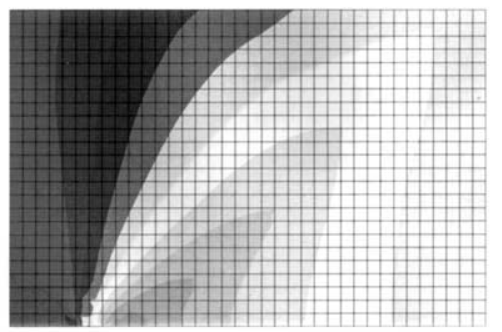

(3)

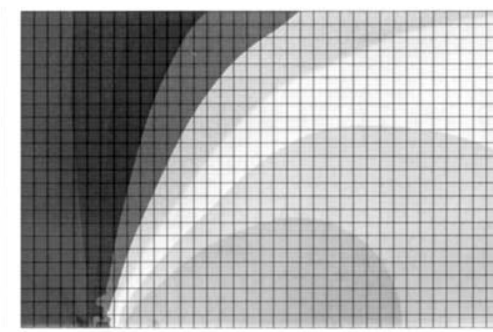

(2)

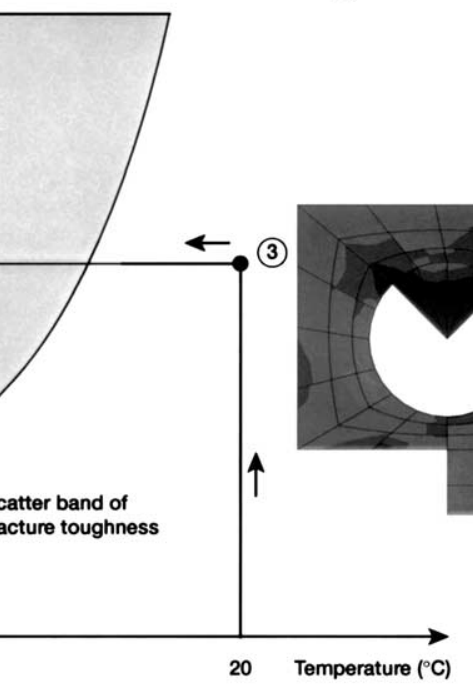

Fig. 8. Evolutions of the maximum principle stress at the crack tip at three different stages of LCF cycle: at the beginning (8-3) and the end (8-2) of cooling, at a cumulative fracture probability equal to 1 (8-1). Stress range from $-400 \mathrm{MPa}$ (dark) to $1300 \mathrm{MPa}$ (grey, at the crack tip in Fig. (8-1)).

at this time: $f=f(\theta)$. This expression is consistent with the one proposed by Kantidis et al. (1994) in the context of intergranular brittle fracture.

Of course this new parameter does not change previous expressions for isothermal conditions. Conversely, considering a full thermomechanical loading, the cumulative fracture probability is modified in the following way: if $\theta(t)$ denotes the temperature in $\mathrm{d} V$ at time $t$, condition (Eq. (9)) reads:

$$
\begin{aligned}
& \sigma_{\mathrm{c}} \geq \sigma_{1(\text { micro })}= \\
& \quad f(\theta(u)) \sigma_{1}(u), \forall u \leq t, \text { such as } p(u)>0,
\end{aligned}
$$

so that: $p_{\mathrm{r}}(t)=\left(\max _{\{u \leq t, p(u)>0\}} \frac{\sigma_{1}(u)}{\sigma_{\mathrm{u}}(\theta(u))}\right)^{m}$

where the cleavage stress is now a temperature dependent parameter given by:

$\sigma_{\mathrm{u}}(\theta)=\frac{\sigma_{\mathrm{u}}}{f(\theta)}$.

As expected (see also Kantidis et al., 1994), the critical stress issued from Griffith analysis (relation Eq. (1)) remains temperature independent. Actually, the apparent temperature dependence of the macroscopic cleavage stress results directly from the thermal dependence of mechanical fields surrounding microcracks.

The cumulative fracture probability of the component at any given time $t$ reads: 
$P_{\mathrm{r}}(t)=1-\exp \left(-\int_{\Omega}\left(\max _{\{u \leq t, p(u)>0\}} \frac{\sigma_{\mathrm{l}}(u)}{\sigma_{\mathrm{u}}(\theta(u))}{ }^{m} \frac{\mathrm{d} V}{V_{0}}\right.\right.$.

Alternatively, we notice that another expression could be:

$P_{\mathrm{r}}(t)=1-\exp \left(-\int_{\Omega}\left(\max _{\{u \leq t, \dot{p}(u)>0\}} \frac{\sigma_{1}(u)}{\sigma_{\mathrm{u}}(\theta(u))}\right)^{m} \frac{\mathrm{d} V}{V_{0}}\right)$,

which only differ from the former one by integrating on active plastic zone (i.e. $\dot{p}(t)>0$ ) instead of cumulated plastic zone. Is this condition in contradiction with original Beremin model? Formally, the answer is obviously no, given that it reduces to the classical one as soon as the loading is monotonically increasing. Even from a physical point of view, the answer is no again, provided that an additional propagation condition is slip activity. This propagation condition is consistent, but more restrictive, than the nucleation one. Waiting for additional experimental investigations, expression (Eq. (17)) is, therefore, as relevant as (Eq. (16)) considering unloading effects on cleavage fracture.

In view of the following simulations, two modified Beremin model expressions arise from this work. The cumulated plastic zone modified (CPZM) Beremin model in contrast with the active plastic zone modified (APZM) one will refer in the following to expressions Eqs. (16) and (17), respectively. It is worth emphasizing that they are both consistent with the classical Beremin model previously derived in the more restrictive case of increasing mechanical loading. But these new ex-

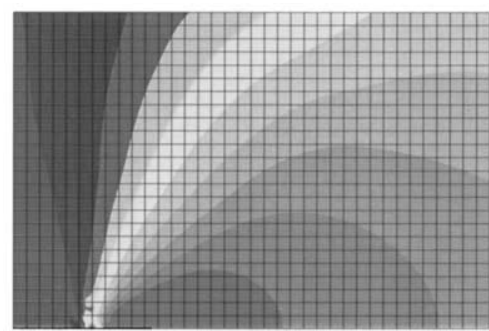

(1)

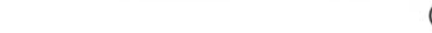

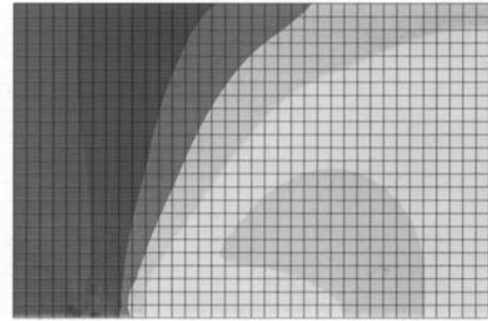

(2)

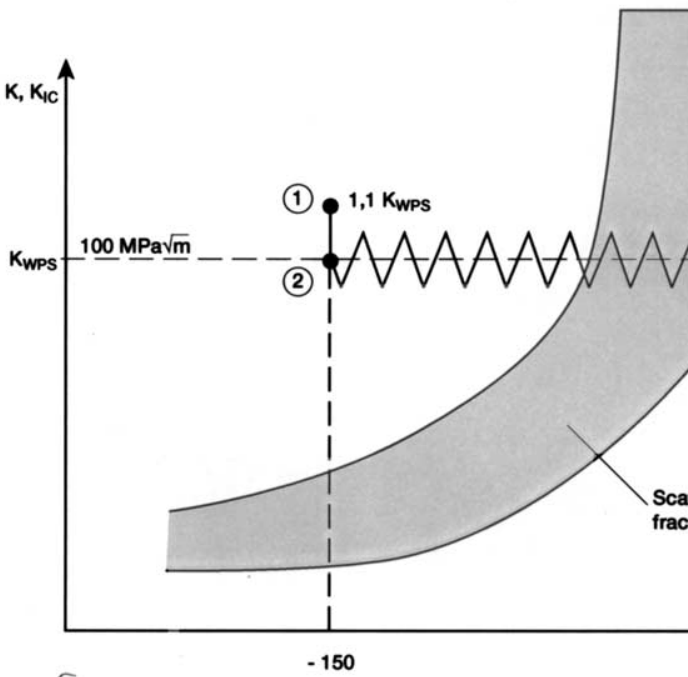

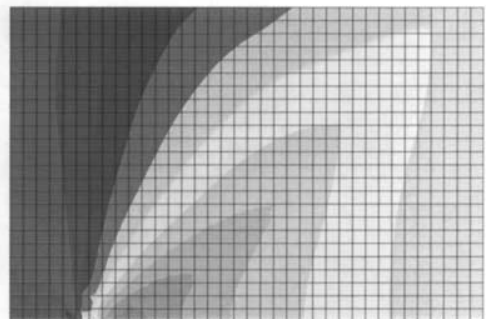

(3)

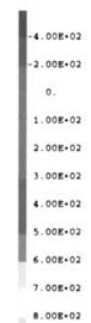

Fig. 9. Evolutions of the maximum principle stress at the crack tip at three different stages of LOCF cycle: at the beginning (9-3) and the end (9-2) of cooling, at a cumulative fracture probability equal to 1 (9-1). Stress range from $-400 \mathrm{MPa}$ (dark) to $1300 \mathrm{MPa}$ (grey, at the crack tip in Fig. (9-1)). 


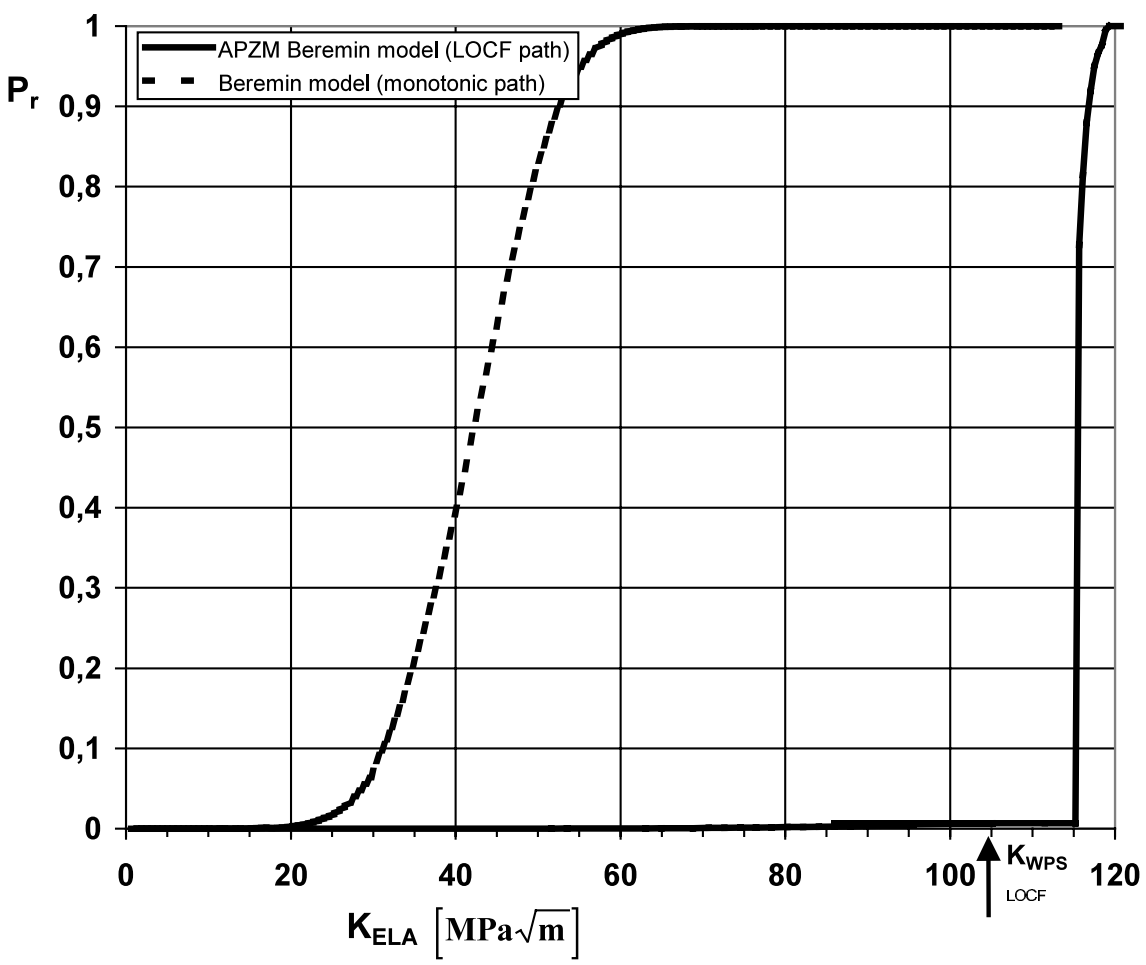

Fig. 10. Evolution of the cumulative fracture probability as a function of the elastic stress intensity factor during the LOCF cycle as predicted by the APZM Beremin model (continuous line). Evolution corresponding to the monotonic mechanical loading at $-150{ }^{\circ} \mathrm{C}$ is also reported (dotted line). The level of warm prestressing is indicated by a black arrow.

pressions are more general and correctly account for mechanical and thermal unloading effects. Unlike previous results (see Kordisch et al., 2000), they both ensure the cumulative probability to be an increasing function of time, even for non monotonic loading.

\section{Results}

In this section, we aim at applying the modified Beremin models derived in the previous section to simulate WPS experimental results obtained recently. The test material is $18 \mathrm{MND} 5$ ferritic steel. Its chemical composition is reported in Table 1. Tensile true stress-strain curves of this steel at five different temperatures $(20,-20,-50$, 100 and $-150{ }^{\circ} \mathrm{C}$ ) are reported in Fig. 1.

\subsection{Identification of Beremin model parameters}

To describe the whole fracture toughness transition curve, the Beremin model parameters have been fitted on CT25 (1T-CT) experiments. The corresponding Finite Element calculations are described in more details further (see Section 3.3). Fracture toughness at $20,-20,-50,-100$ and $-150{ }^{\circ} \mathrm{C}$ is given in Fig. 2. The Weibull modulus as well as the cleavage stress have been fitted on these data thanks to the maximum likelihood method (see for instance Khalili and Kromp, 1991). The corresponding results are reported in Table 2 while predictions of fracture toughness are compared with experimental results in Fig. 2. It is worth emphasizing that no strain correction was taken into account in this identification when computing the Weibull stress. This point could 
also explain the apparent increase of the cleavage stress between -150 and $-20{ }^{\circ} \mathrm{C}$ (approximately $30 \%$ ). Nevertheless, and as explained hereafter (see Section 3.4), values of the Beremin parameter above $-150{ }^{\circ} \mathrm{C}$ will not substantially modify the following results.

\subsection{Experimental WPS results}

CT-25 with $20 \%$ side-grooved specimens have been used for the considered WPS experiments (see geometry on Fig. 3). All specimens have first been mechanically loaded at $20{ }^{\circ} \mathrm{C}$. During this first stage, the load is controlled by the elastic stress intensity factor derived explicitly from both the loading force $P$ and the crack $a_{0}$, namely (see ASTM, 1989 E399):

$K=\frac{P}{\sqrt{B B_{\mathrm{N}} W}} F\left(\frac{a_{0}}{W}\right)$
( $B$ is the total thickness of the specimen ( $W=$ $2 B), B_{\mathrm{N}}$ is the reduced crack plane thickness and $F$ is a tabulated function). During the unloading stage, various thermomechanical paths were experienced. All the corresponding experimental results agree with the WPS effect. Notice that the scatter band appears to be much smaller than the virgin material one in agreement with previous results (see Roos and Elsäser, 1997). These experimental results are broadly depicted in Lefevre et al. (2000).

For the simulations, we consider the following cycles (see Fig. 4(a)).

- Load cool fracture (LCF).

- Load unload cool fracture (LUCF).

- Load oscillation cool fracture (LOCF).

For a warm prestress up to $100 \mathrm{Mpa} m^{1 / 2}$ (approximately $40 \%$ of the material toughness at $20{ }^{\circ} \mathrm{C}$ ), three different tests have been performed for LCF as well as LUCF loading paths. For the

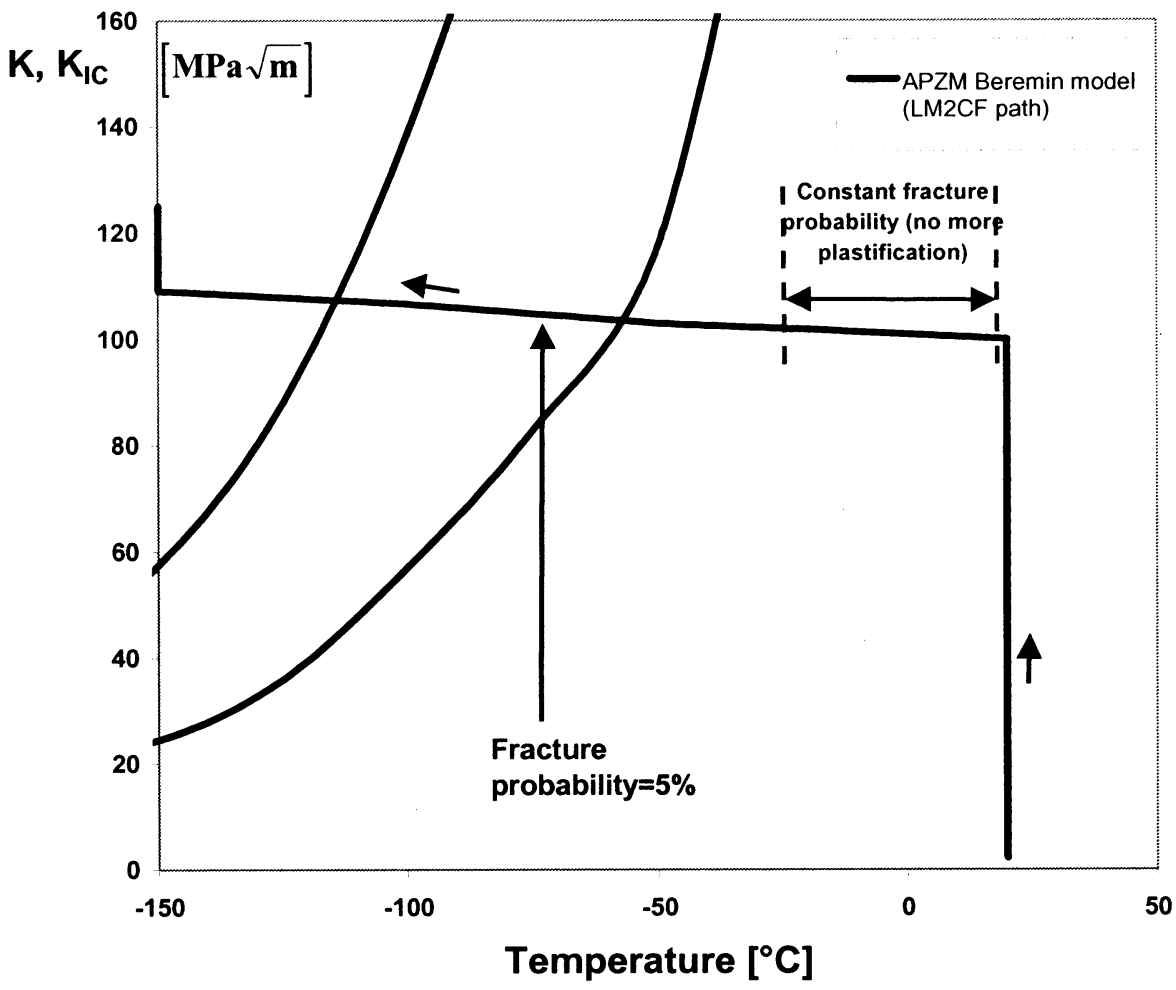

Fig. 11. Evolution of the elastic stress intensity factor as a function of temperature during a LM2CF cycle as predicted by the APZM Beremin model. The point corresponding to a cumulative fracture probability equal to $5 \%$ is indicated by a black arrow. 


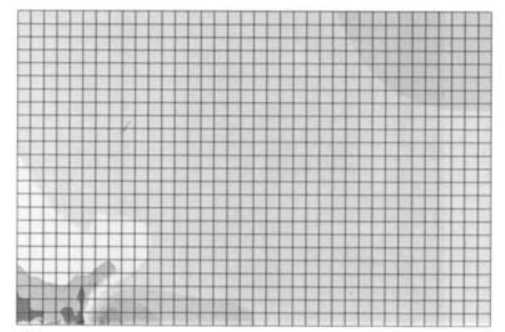

(1)

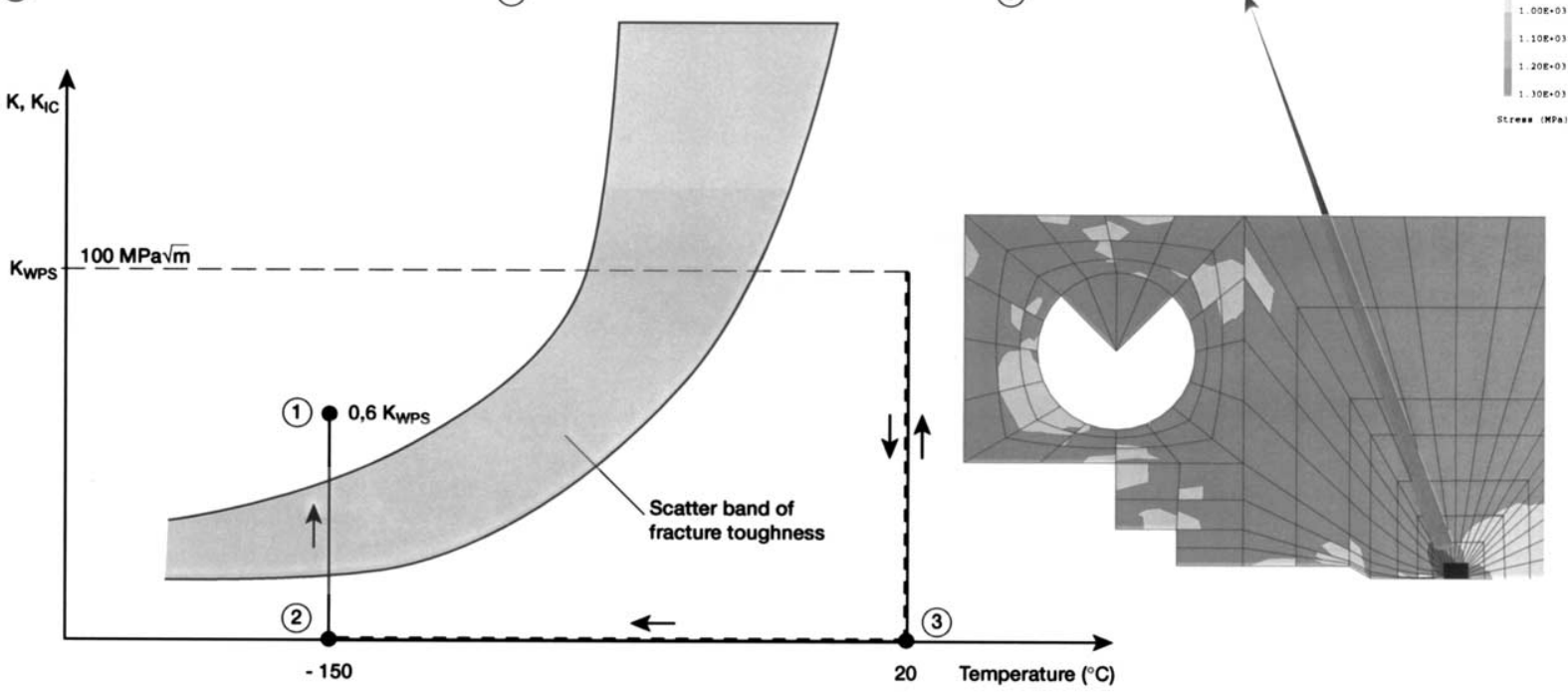

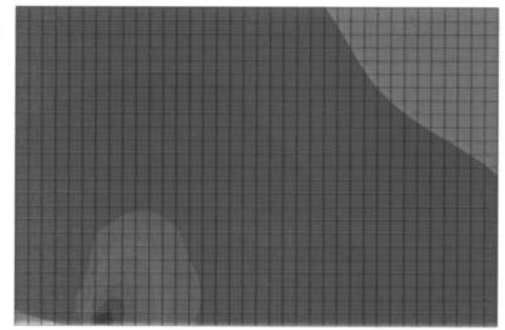

(2)
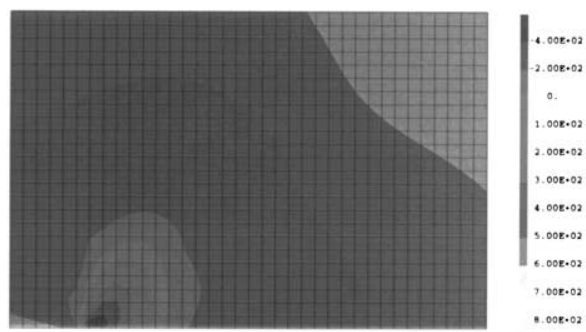

0.03

Fig. 12. Evolution of the maximum principle stress at the crack tip at three different stages of LUCF cycle: at the beginning (12-3) and the end (12-2) of cooling, at a cumulative fracture probability equal to 1 (12-3). Stress range from - $400 \mathrm{MPa}$ (dark) to 1300 MPa (grey, at the crack tip in Fig. (12-1)).

LOCF cycle, two experiments corresponding to a lower warm prestress $\left(60 \mathrm{Mpa} \mathrm{m}^{1 / 2}\right)$ were performed. All the corresponding results are reported in Table 3. The conservative principle associated to WPS is obtained: no fracture was experienced during unloading stages.

A Load-Maintained Crack opening displacement during cooling-fracture (LM2CF) cycle was also tested (Valeta et al., 1999). In Fig. 4(b) we have reported the corresponding evolution of the (elastic) stress intensity factor with temperature. Unlike previous tests, the stress intensity factor increases during the cooling stage. That is the reason why cleavage fracture occurred during this stage.

\subsection{Finite element calculations}

To save computing time, a two dimensional mesh was used to perform finite element calculations. Moreover, we take advantage of symmetry to mesh only one half of the specimen (see Fig. 5). Nonlinear quadratic elements with plane strain conditions were used. The principle stress $\sigma_{1}$ in one element is computed from the mean stress tensor over the four Gauss points. Fifty microns square elements were used at the crack tip. The mesh has 3556 nodes and 1239 elements.

A von Mises rate independent elastoplastic behavior with isotropic hardening fitting the experimental tensile curve at each temperature from 
-150 to $20{ }^{\circ} \mathrm{C}$ was used (linear interpolations between experimental tensile curves were used at intermediate temperatures). For the LUCF cycle, a kinematic hardening law has also been used (additional calculations have shown that LCF, LOCF and LM2CF simulations with isotropic or kinematic hardening do not differ significantly). This kinematic hardening law reads:

$$
\left\{\begin{array}{l}
(\underline{\underline{\sigma}}-\underline{\underline{X}})_{\mathrm{eq}}=\sigma_{0} \\
\underline{\underline{X}}=\frac{-}{3} C \underline{\underline{\alpha}}, \underline{\underline{\dot{\alpha}}}=\underline{\underline{\dot{\varepsilon}}}^{\mathrm{p}}-\gamma \underline{\underline{\alpha}} \dot{p}
\end{array}\right.
$$

The two parameters $C$ and $\gamma$ as well as the yield stress $\sigma_{0}$ are temperature dependent. They have been fitted (see Table 4) on the experimental tensile curves:

$\sigma=\sigma_{0}+\frac{C}{\gamma}\left(1-\exp \left(-\gamma \varepsilon^{\mathrm{p}}\right)\right)$
( $\sigma$ and $\varepsilon^{\mathrm{p}}$ are the axial stress and plastic strain).

Loading is simulated as an imposed vertical force applied to the CT pinhole center. To apply this load to the specimen, one fourth of the pin, assumed to be elastic, was modeled. During cooling stages, temperature fields are considered as uniform throughout the specimen.

\subsection{Comparison with experiments}

In Fig. 6, we have compared LCF cycle simulations to experiments (the experimental mean fracture toughness at $-150{ }^{\circ} \mathrm{C}$ is slightly higher than $40 \mathrm{Mpa} \mathrm{m}^{1 / 2}$ ). Unlike experimental results, the cumulative fracture probability as predicted by CPZM Beremin model increases during the cooling stage. Actually, the plastic zone formed during the load at $20{ }^{\circ} \mathrm{C}$, unloads elastically (see Fig. 7)

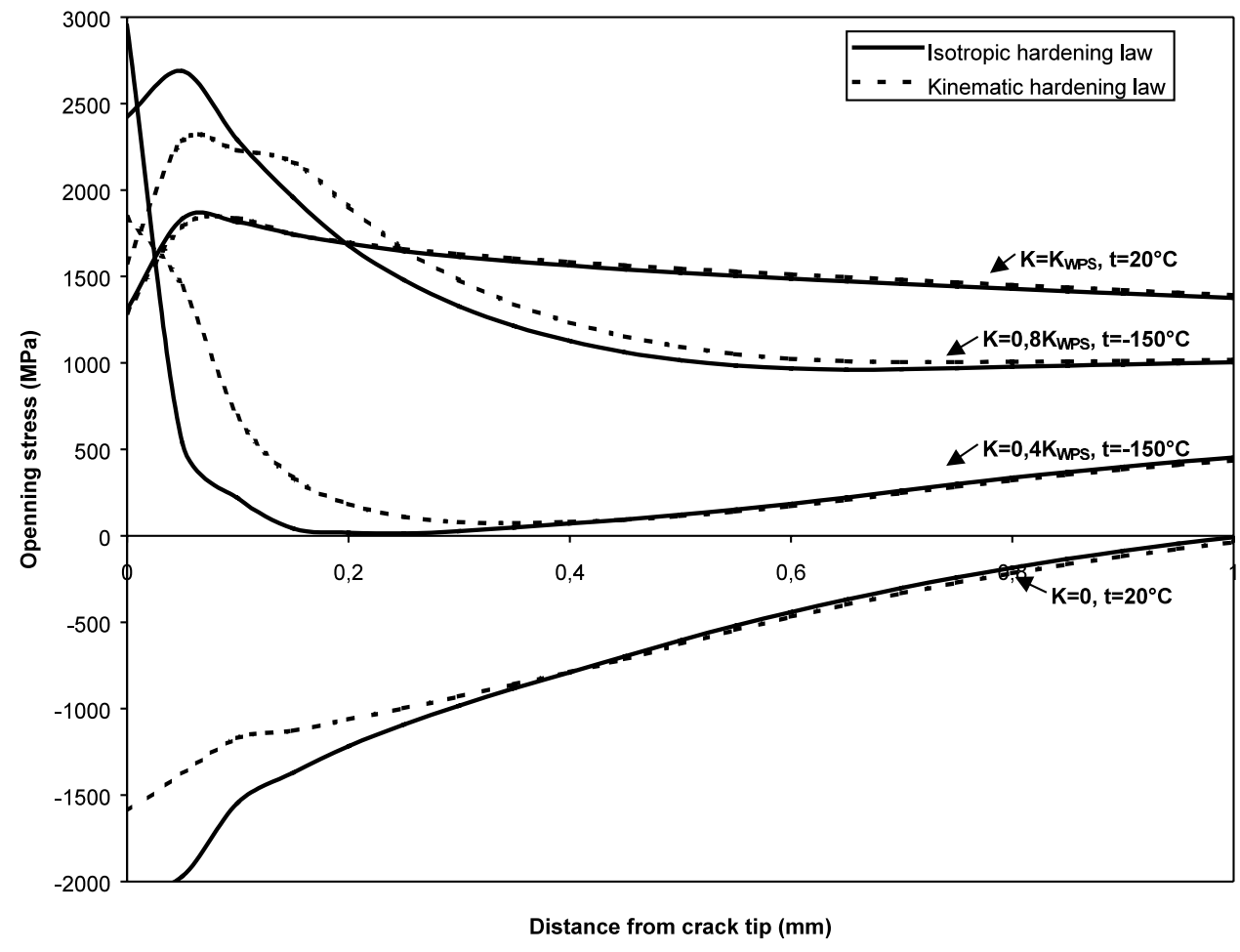

Fig. 13. Opening stress distribution ahead of the crack tip at various steps of the LUCF cycle, as predicted by the isotropic (continuous line) as well as kinematic (dotted line) hardening constitutive laws. 


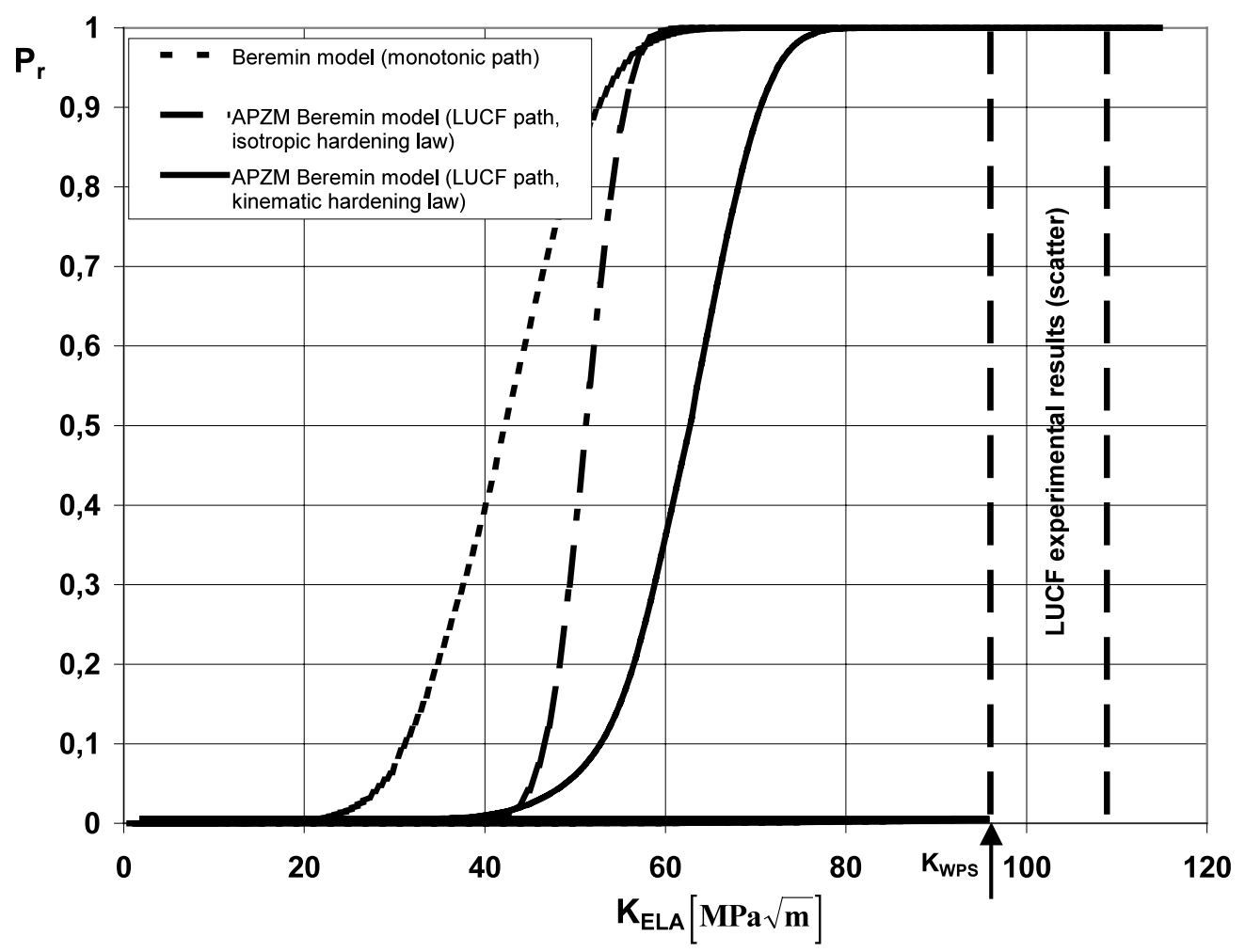

Fig. 14. Evolution of the cumulative fracture probability as a function of the elastic stress intensity factor during the LUCF cycle as predicted by the APZM Beremin model with an isotropic hardening law (dotted-dashed line) as well as a kinematic one (continuous line). Evolution corresponding to the monotonic mechanical loading at $-150{ }^{\circ} \mathrm{C}$ is also reported (dotted line). These results are compared with the experiments (the level of warm prestressing is indicated by a black arrow).

and mechanical fields remain approximately constant as reported on Fig. 8. Simultaneously, the cleavage stress parameter decreases driving the growth of the fracture probability.

To improve this result we adopt the alternative expression (Eq. (17)) of the cumulative fracture probability (i.e. APZM Beremin model). Now, the instantaneous potential cleavage sites are those located within the active plastic zone. The corresponding results are also reported on Fig. 6. As a consequence of cooling, the initial plastic zone unloads elastically so that the fracture probability does not evolve anymore in agreement with experiments. A related result is the brutal growth of fracture probability as soon as plastic flow occurs during loading at $-150{ }^{\circ} \mathrm{C}$ reducing strongly the predicted scatter band in agreement with experimental results. Therefore, LCF cycle simulation as predicted by the APZM Beremin model compares advantageously with experimental results.

We have also simulated the LOCF cycle (Figs. 9 and 10) as well as the LM2CF one (Fig. 11) with the APZM Beremin model. Considering first the LOCF, with a warm prestress equal to 100 Mpa $m^{1 / 2}$, the maximum principal stress field evolution at the crack tip is qualitatively similar to the LCF one (see Fig. 9). As expected, the stress field at fracture is more severe than the LCF one since the warm prestress level is higher. Fig. 10 displays a reduction of the toughness scatter band around a mean toughness approximately $10 \mathrm{Mpa} m^{1 / 2}$ higher than the warm prestress one. The LOCF experimental results are not reported in Fig. 10 as they correspond to a warm prestress equal to $60 \mathrm{Mpa} m^{1 / 2}$ only.

In Fig. 11, the evolution of the elastic stress 
intensity factor as a function of temperature is depicted for LM2CF cycle. Increase of load during cooling causes two opposite effects: stresses increase with the load near the crack tip while the active plastic zone decreases with temperature. As a result, the cumulative fracture probability does not necessarily increase. Here, the plastic zone is first frozen so that the fracture probability does not increase with the load during cooling (the corresponding times are indicated in Fig. 11). Then, the active plastic zone spreads causing the growth of fracture probability. An arrow indicates when this probability reaches $5 \%$ on this curve. Cleavage fracture, as predicted by the APZM Beremin model, can, therefore, be experienced for LM2CF cycles.

Finally, the whole loading path of LUCF cycle has been simulated. The unloading stage occurring during this cycle induces high compressive residual stresses at the crack tip (see Fig. 12). This residual stress field as well as opening stresses during the final loading (i.e. loading at $-150{ }^{\circ} \mathrm{C}$ ) depend on the material constitutive behavior. Therefore, we have substituted the isotropic hardening law by the kinematic one (see equation (Eq. (18))) to simulate this cycle. Corresponding evolutions of the opening stress distribution ahead of the crack tip have been compared with the ones given by the isotropic hardening law in Fig. 13. According to this figure, stress distribution calculated with the kinematic hardening law is both smoother and lower in the near tip region than the one calculated with the isotropic hardening law. As a consequence, the evolution of the specimen cumulative fracture probability as a function of the elastic stress intensity factor as predicted by the APZM Beremin model is less conservative with the kinematic hardening law than with the isotropic one (see Fig. 14). The CPZM Beremin model gives almost identical results. But numerical simulations remain far below experimental results. One reason why could be that the localization parameter $f(\theta)$ from macroscopic to microscopic stresses is affected by the tensioncompression cycle. However, deriving definite conclusions from these simulations needs to determine the relative parts of both isotropic and kinematic hardening for this steel. Tension-com- pression tests on 18MND5 steel should be performed to clarify this point. In addition, a 3D calculation should be interesting too.

\section{Conclusions}

In this paper, we have extended the original Beremin model to general thermomechanical loading paths. As a consequence of the effect of temperature on mechanical fields heterogeneity, an apparent temperature dependence of the cleavage stress has been introduced. The corresponding simulations compare advantageously with WPS experiments provided that plastic zone is substituted by active plastic zone when integrating the cumulative fracture probability. According to this APZM model, the cumulative fracture probability of a component reads:

$P_{\mathrm{r}}(t)=1-\exp \left(-\int_{\Omega}\left(\max _{\{u \leq t, \dot{p}(u)>0\}} \frac{\sigma_{1}(u)}{\sigma_{\mathrm{u}}(\theta(u))}\right)^{m} \frac{\mathrm{d} V}{V_{0}}\right)$

This expression reduces to the classical one:

$P_{\mathrm{r}}(t)=1-\exp \left(-\int_{\Omega}\left(\frac{\sigma_{1}(t)}{\sigma_{\mathrm{u}}}\right)^{m} \frac{\mathrm{d} V}{V_{0}}\right)$

for monotonically increasing isothermal mechanical loading.

Some improvements could be taken in consideration. First, fitting of Beremin parameters in the transition zone including strain correction of the Weibull stress as well as ductile tearing could be introduced. However, we have shown that the condition of active plastic zone 'freezes' the cumulative fracture probability during cooling. Apart from cycles as LM2CF (i.e. increasing loading during cooling), this first improvement will not substantially modify the predicted fracture toughness.

More interesting would be to improve the simulations of LUCF cycle. The calculations have shown the effect of the hardening law (i.e. isotropic or kinematic) on failure probability predictions. This result is consistent with the previous one given in Stockl et al. (2000). Tension-compression tests on 18MND5 steel are now needed 
to identify the relevant hardening law. Next simulations should include 3D calculations too. The effect of the Tension-compression cycle on the mechanical fields heterogeneity at the microscale could also be investigated.

Finally, it is worth mentioning that our 'active plastic zone modified Beremin model' (APZM) is consistent with former works (Beremin, 1981) based on the RKR cleavage fracture model (Ritchie et al. (1973)). To simulate WPS cycles, a condition of 'advent of plasticity at the crack tip' had already to be introduced.

However, the physical meaning of the 'active plastic zone' condition should also be studied with future experimental works. Particularly, it would be worth clarifying whether slip activity is required for propagating cleavage microcracks.

\section{Acknowledgements}

Experimental data mentioned in this study are part of the 'MPA-EDF collaboration on the WPS Effect' (W. Lefevre was in stay at MPA during this collaboration). Fruitful discussions with U. Eisele and his coworkers, are gratefully acknowledged.

\section{References}

ASTM, 1989. Standard test method for J1C, a measure of fracture toughness E813-89.

Beremin, F.M., 1981. Numerical modeling of warm prestressing effect using a damage function for cleavage fracture. In: François, D. (Ed.), ICF 5, Advance in Fracture Research, vol. 2, pp. 825-832.

Beremin, F.M., 1983. A local criterion for cleavage fracture of a nuclear Pressure Vessel Steel. Met. Trans. A 14A, $2277-$ 2287.
Brothers, A.J., Yukawa, S., 1963. The effect of warm prestressing on notch fracture strength. J. Basic Eng. 97 TRANS. ASME, Series D, vol. 85, m01, 87-104.

Cottrell, A.H., 1958. Theory of brittle fracture in steel and similar metals. Trans. Metall. Soc. AIME 212, 192-203.

Griffith, A.A., 1920. The phenomena of rupture and flow in solids. Phil. Trans. Roy. Soc. London A221, 163-198.

Khalili, A., Kromp, K., 1991. Statistical properties of Weibull estimators. J. Mater. Sci. 26, 6741-6752.

Kantidis, E., Marini, B., Pineau, A., 1994. A criterion for intergranular brittle fracture of a low alloy steel. Fatigue Fract. Eng. Mater. Struct. 17 (6), 619-633.

Kordisch, H., Böschen, R., Blauel, J.G., Schmitt, W., Nagel, G., 2000. Experimental and numerical investigations of the warm-prestressing (WPS) effect considering different load paths. Nucl. Eng. Des. 198, 89-96.

Lefevre, W., Eisele, U., Valeta, M.P., Barbier, G., 2000. Structural behavior during a PTS transient taking into account the WPS effect. IAEA Specialists' meeting, Rockville.

Lidbury, D., Birkett, P., 1990. In: Gudas, J.P., Joyce, J.A., Hackett, E.M. (Eds.), Effect of Warm Pre-Stressing on the Transition Toughness Behaviour of an A533 Grade B Class 1 Pressure Vessel Steel. Fracture Mechanics: 21st Symposium ASTM STP 1074. ASTM, Philadelphia, pp. 264-285.

Mudry, F., 1985. Cleavage fracture and transition: application to the warm prestress effect. In: Elastic Plastic Fracture Mechanics. ECSC, EEC, EAEC, Brussels and Luxembourg, pp. 303-325.

Ritchie, R.D., Knott, J.F., Rice, J.R., 1973. On the relationship between critical tensile stress and fracture toughness in mild steel. J. Mech. Phys. Solids 21, 395-410.

Roos, E., Elsäser, K., 1997. Experimental and numerical investigation on the applicability of local approach methods on warm prestress effect. Twenty-third MPA-seminar on Safety and Reliability of Plant technology, Stuttgart.

Stockl, H., Boschen, R., Schmitt, W., Varfolomeyev, I., Chen, J.H., 2000. Quantification of the warm prestressing effect in a shape welded $10 \mathrm{MnMoNi}$ 5-5 material. Eng. Fract. Mechanics 67, 119-137.

Stroh, A.N., 1954. The formation of cracks as a result of plastic flow. Proc. Roy. Soc. A223, 404-414.

Valeta, M.P., Sainte-Catherine, C., Barbier, G., Lefevre, W., Bandhari, S., 1999. Analysis on the influence of the loading applied during the cooling phase of WPS tests. Twentyfifth MPA-seminar on Safety and Reliability of Plant technology, Stuttgart. 